\section{Terapia cognitivo-comportamental na prática psiquiátrica}

Paulo Knapp et al

São Paulo: Artmed Editora; 2004

Neste recente livro editado pelo colega gaúcho Paulo Knapp et al, os leitores brasileiros passam a contar com uma obra que é, ao mesmo tempo, abrangente, didática e contribui enormemente para a prática clínica psiquiátrica atual. Abordando a terapia cognitivo-comportamental (TCC) sob diversos ângulos, esta publicação certamente tornar-se-á, nos próximos anos, o livro-texto em nosso meio desta modalidade de tratamento psicossocial que é a mais pesquisada e validada em todo o mundo. A importância deste livro para a prática psiquiátrica brasileira, penso, se fará sentir gradualmente nos próximos anos na medida em que mais e mais leitores forem tomando conhecimento desta obra.

Abrangente, do ponto de vista teórico-prático, o livro é dividido em três partes que somam trinta e três capítulos. Na primeira parte são descritos os fundamentos científicos da TCC. O organizador desta edição abre o livro com um capítulo que já nos dá uma idéia das linhas gerais da obra. O leitor, de pronto, é colocado em contato com os princípios teóricos desta abordagem psicoterápica, como crenças disfuncionais, esquemas e pensamentos automáticos, e recebe um diagrama de conceitualização cognitiva para ser utilizado na prática diária. E este será, ao longo de todo o livro, o rumo adotado pelos autores: a mescla de conceitos teóricos com a aplicação na prática psiquiátrica atual. A partir deste excelente capítulo introdutório, o leitor passa a conhecer aspectos históricos da TCC para, em seguida, serem abordados temas fundamentais para o modelo cognitivo-comportamental, como a extinção das memórias no processo terapêutico, a neurobiologia do comportamento, as funções executivas, aspectos integradores entre pesquisa experimental e TCC. Esta primeira parte é terminada com um excelente capítulo que aborda o modelo cognitivo das alucinações escrito por ninguém menos que o próprio fundador da TCC, Aaron Beck, o que passa a figurar como um atestado da correção da presente obra brasileira.

Na segunda parte, então, o leitor recebe inúmeros registros para serem feitos quando da aplicação da técnica nos diversos transtornos psiquiátricos e são demonstrados os bons resultados da TCC na prática clínica baseada em evidências - como requer o momento atual. A partir daí, o livro passa a abordar, de forma bastante ampla, consistente e prática, o papel da TCC na depressão, no Transtorno Obsessivo-Compulsivo (TOC), Transtorno de Ansiedade Generalizada (TAG), Pânico, Fobia Social, Fobias específicas, Transtorno de estresse pós-traumático (TEPT), dependência química, Transtornos alimentares, Transtornos de personalidade, Transtorno de Humor Bipolar (THB), Esquizofrenia e disfunções sexuais, e termina com dois capítulos dedicados a crianças e adolescentes: transtornos de ansiedade e Transtorno de Déficit de Atenção com Hiperatividade (TDAH). Desta segunda parte, muito bem escrita por vários colegas com ampla experiência prática nos mais diversos transtornos psiquiátricos, o leitor brasileiro com certeza sentir-se-á habilitado a adotar a TCC na sua rotina psiquiátrica, se assim o desejar.
O livro termina, na sua terceira parte, com tópicos especiais sobre aspectos mais específicos da própria prática psiquiátrica nos quais a TCC pode também contribuir enormemente, como a terapia de casais e famílias, a reeducação alimentar, as habilidades sociais, dentre outros.

Mas, e acima de tudo, este livro conta com 56 capacitados autores nacionais e internacionais. Penso que esta é a contribuição fundamental do livro para a Psiquiatria brasileira: a abordagem prática da TCC a partir da experiência clínica de inúmeros colegas (a maioria brasileiros, de diversos centros do país) alicerçados na boa teoria e em evidências científicas. Talvez, o intuito mesmo desta obra esteja na apresentação que o próprio Aaron Beck faz deste livro: "Ainda há muito trabalho a fazer e, à medida que os estudos com populações brasileiras formarem um corpo de pesquisas, espero que, num futuro próximo, os pesquisadores, estudiosos e terapeutascognitivos brasileiros também possam acrescentar novos desenvolvimentos à característica de constante evolução e inovação da terapia cognitiva." Certamente, Paulo Knapp et al, com esta obra, contribuem em muito para toda uma linha de desenvolvimento, tanto de pesquisa, quanto da prática psiquiátrica em nosso país.

\section{Flávio Shansis}

Mestre em Bioquímica pela UFRGS, Curso de Terapia Cognitiva pelo Beck Institute, Philadelphia

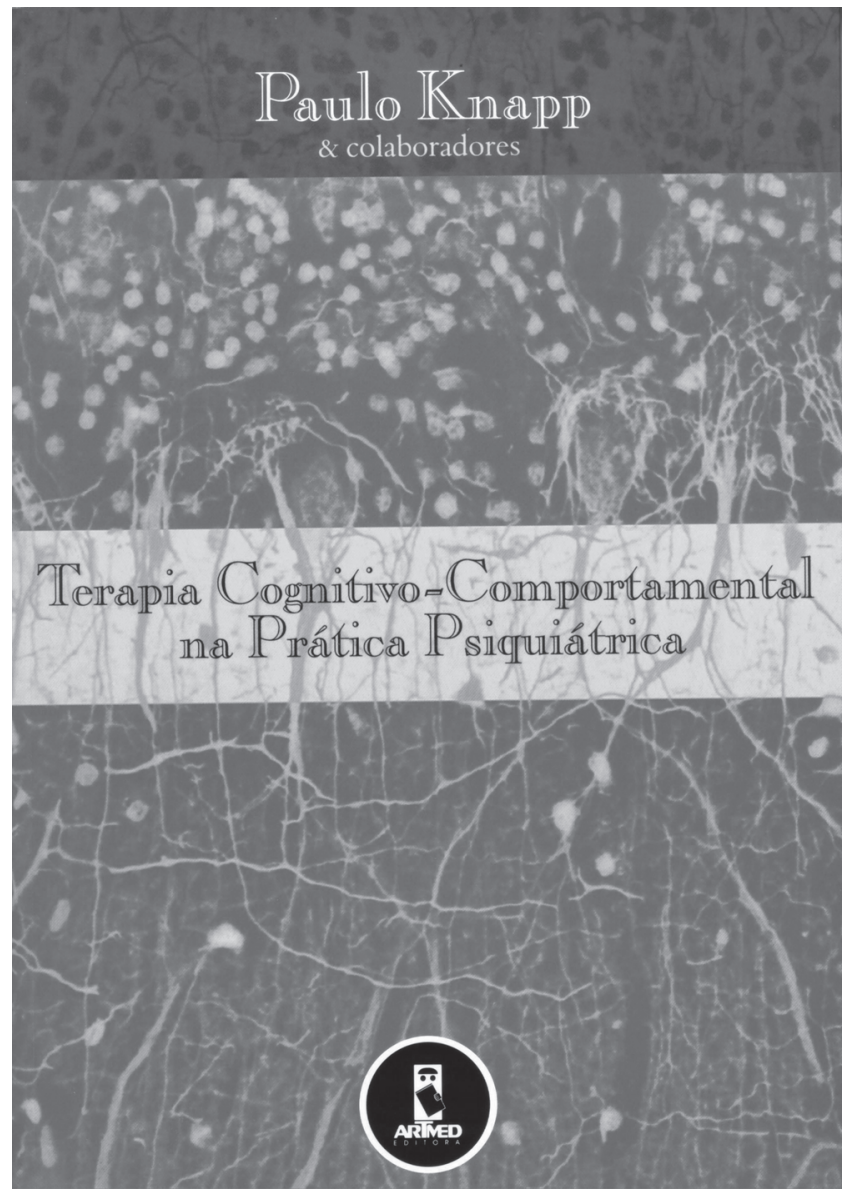

